\title{
Perception of childhood convulsion among women in a peri-urban community in Ilorin, Nigeria
}

\author{
Emmanuel Ademola Anigilaje ${ }^{1}$, Omolara Olufunmilayo Anigilaje ${ }^{2}$ \\ ${ }^{1}$ Department of Paediatrics, College of Medicine, Benue State University, Makurdi, Nigeria \\ ${ }^{2}$ Department of Paediatrics, Federal Medical Centre, Makurdi, Nigeria
}

\begin{abstract}
Background: Poor understanding of childhood convulsion among parents contributes largely to morbidity and mortality resulting from convulsion in developing countries.

Aims and Objectives: This study evaluated the knowledge and attitude of women regarding childhood convulsion in Tegbesun, a peri-urban community in Ilorin, Nigeria.

Methods: This community based study comprised of 500 women aged between 18 and 65 years who were interviewed using a structured questionnaire and a focused group discussion among 10 women within the study group.

The results: Clenching of the teeth (100\%) was the commonest biomedical description for convulsion. $69.8 \%$ of subjects believed that a child dies temporarily during convulsion but regains life post-ictally. Subjects also attributed "angry gods" (51.8\%), "evil spirit" (49.0\%), "constipation" (36.8\%) and "black blood" (0.6\%) to be causes of childhood convulsion. Lack of maternal formal education was found to significantly influence poor knowledge about childhood convulsion.

Conclusion: The study underscored the paucity of knowledge on childhood convulsion. Health information was given in the community to mothers, teachers and health workers regarding the causes, treatment and prevention of childhood convulsions.
\end{abstract}

Keywords- Childhood-Convulsion, Perception, Peri-urban, Ilorin, Nigeria.

\section{INTRODUCTION}

Convulsion does not constitute a diagnosis but is a symptom of an underlying central nervous system disorder that requires a thorough investigation and management plan.[1] Convulsions are most commonly associated with fever and constitute a syndrome of febrile convulsions among children between the ages of 6 months and 6 years. [2,3] Febrile convulsion is thus a convulsion precipitated by a febrile illness in the absence of an infection of the central nervous system and it constitutes the main cause of convulsions among the susceptible age group in Nigeria.[2-5] The prevalence of febrile convulsions thus ranges from $8.08 \%$ in Jos, [2] $11.5 \%$ in Ilorin, [3] $15.1 \%$ in Ibadan, [4] and $15.6 \%$ in Enugu. [5] When convulsions are recurrent and are unrelated to fever or to an acute cerebral insult it is referred to as Epilepsy. [1] Most cases of epilepsy result from head injuries, central nervous system infections, birth injuries, vascular diseases, intracranial tumours, toxic metabolic and neurocutaneous syndrome. [6,7] In Nigeria, like in other developing countries, when the cause of seizures cannot be determined, a diagnosis of idiopathic epilepsy is made .Studies on the prevalence of epilepsy in Nigerian children have been scanty, but a prevalence of $0.31 \%$ was reported in Lagos by Dada, [8 $]^{\mathrm{l}}$ while Izuora and Azubuike [5] reported a prevalence of $11.8 \%$ in Enugu. Although the outcome for most uncomplicated seizures in children is good, $10-20 \%$ have persistent seizures refractory to drugs, and this poses a diagnostic and management challenge.[1] The outcome of seizures is particularly poor in developing countries like Nigeria where various erroneous traditional beliefs about the aetiology of convulsions abound and harmful practices for the treatment of convulsions are in a common place. [9] The studies by Okoji [10] Anochie, [11] Fagbule [3] and Agyo [2] on the knowledge, attitude and practices (KAP) of home management of childhood convulsion in Nigeria have been hospital based. The researchers retrospectively surveyed for possible home treatment given to children who were admitted to the hospitals for convulsion. These studies cannot therefore be exempted from the pitfalls of such retrospective studies and they failed to give the in-depth knowledge about the perception of mothers regarding childhood convulsion

Although, Ofovwe [12] determined the KAP of home management of febrile convulsions among rural mothers in two Edo Villages, their findings probably would reflect the influence of socio-cultural and religious beliefs on childhood convulsion, in the Southern state of Nigeria.

It is however important that mothers -which are often the caregiver at home caring for children in our setting- understand childhood convulsion and should be capable of intervening safely to apply first aid measure for childhood convulsion. This can only be achieved if mothers' understanding and attitudes toward childhood convulsion are well documented. 
The present community based, door -to- door study, therefore determined for the first time, the knowledge and attitude of women regarding childhood convulsions in Tegbesun, a peri-urban community in Ilorin, Northern, Nigeria.

\subsection{Description of Study}

\section{METHODS}

It was a descriptive cross-sectional study that spanned February and March 2010 in Tegbesun, a community located about 3 kilometres from Ilorin, the Kwara State capital. The village head of Tegbesun was the Alangua, who is under the rulership of the Emir of Ilorin, a Fulani dynasty. The community was connected to the National grid of electricity, enjoyed pipe-borne water and had an accessible federal road. There was one government owned primary and secondary school. Furthermore, there was one Primary Health Centre and many herbal homes that serve the health needs of the people. Tegbesun is one of the communities designated for Community Based Experience and Services (COBES) for medical students of the University of Ilorin and remains a research community of the Department of Epidemiology and Community Medicine of the same University. Ethical clearance was given by the University of Ilorin Research and Ethics Committee. The cooperation of the village head was solicited for through a letter of introduction obtained from the Chairman of the Ilorin East Local Government. The study population consisted of adult females (18 years and above) who are the population often at home to care for children who are ill. A minimum sample size of 384 , for the study was calculated using the formula;

$\mathrm{N}=\frac{(\mathrm{Zi}-\alpha)^{2}(\mathrm{P})(1-\mathrm{P})}{\mathrm{d}^{2}}$

Where Zi- $\alpha=1.96$ (a standard normal deviate)

$\mathrm{p}=0.50$ (the proportion in the target population estimated to have a particular a particular characteristic)

$\mathrm{d}=0.05$ (proportion of sampling error tolerated.

However to accommodate for a non-response rate of $20 \%$, the sample size was rounded off to 500 .

A systematic random sampling was employed. The Primary Health numbers on all the houses in the community were listed. The sampling interval of the houses was calculated by dividing the number of houses by the sample size of 500.The first house was chosen randomly as the centre of the town and the researcher and his survey team then move in the direction of a spurned empty bottle. Selection of all eligible adult females (those that have looked after a child with convulsion) in the selected houses was done until the sample size was obtained. Re-visitations of selected houses were done when women were absent at the initial visits.

The research instrument was a structured questionnaire and a Focused Group Discussion to complement the questionnaire. The study objectives and procedures were explained to the community Head (The Alangua) who nominated an assistant and with whom, the researcher and the survey team conveyed the same purpose to the household heads and the women that were eligible participants. It was emphasized that anyone was at liberty to decline participation and that those participating were also free to withdraw at any stage of the study. The questionnaire instrument contained sections for consent certification by subjects. The questionnaire was pre-tested among 50 adult females in Ogidi, an adjacent community in the same local government area for validity and reliability. The pre-tested questionnaire was then analysed and the necessary corrections made. When Focus Group Discussion (FGD) was done, the consecutive $50^{\text {th }}$ participant was selected, (Labelled W1 to W10). FGD took place at the Alangua's palace and at an agreed date and time but at the Alangua's absence. The discussion took about 90 minutes. Basic open questions bordering on knowledge and attitude of mothers towards childhood convulsion were asked. The survey team consisted of 6 female medical students of the University of Ilorin. These students were fluent in Yoruba language and were also familiar with the culture of the community. They were trained in the administration of the questionnaires adapted in Yoruba language and their proficiency was verified through role-play and pre-testing. The researcher closely supervised the assistants to ensure compliance with the training given. In the FGD session, a debrief was held between the moderator and the tape-recorder to examine the focus group activities and results. The tape recordings were transcribed and reconciled with the notes taken during the FGD

\subsection{Data analysis}

Data collected were checked for errors and then transferred onto a master sheet. Data analysis was done to produce frequency distribution tables. The chi - square test was employed to test the effect of education on the commonest, correct and erroneous description and causes of childhood convulsion.

\section{RESULTS}

Table 1. A total of 500 women between the ages of 18 and 65 years were interviewed. The mean age was 35.5 \pm 4 . 4 years, with the majority falling within 18 and 47 years. 
Table 2. The majority of the participants 473 , (94.6\%) was married. Most of the participants, 406 , were Muslims (81.2\%), the remaining 94 participants (18.8\%) were Christians. $33.4 \%$ had no formal education or attained primary education (33.6\%). 155 subjects $(31.0 \%)$ and another ten subjects $(2.0 \%)$ had secondary and tertiary education respectively. 253 participants (50.6\%) were farmers and another $205(41.0 \%)$ were traders. The majority of the subjects, $495(99 \%)$ were Yorubas and four subjects $(0.8 \%)$ were Ibos. Only one woman was Hausa.

Table 3. All the 500 participants correctly described clenching of the teeth as the commonest biomedical description of convulsion, although 347 participants (69.8\%) also erroneously believed that a child dies during a convulsion, only to regain life post-ictally.

Table 4. Although most participants, correctly agreed that convulsion may be caused by malaria fever $(90.8 \%)$ or hereditary (67.6\%), however 292 participants (58.45) did not know that other childhood febrile illness may precipitate convulsions in the susceptible child. Angry gods, an evil spirit and constipation were thought to cause convulsion in 259 (51.8\%), 245 (49.0\%) and 184 (36.8\%) of participants respectively. Another 3 women $(0.6 \%)$ attributed 'black blood' to be the cause of convulsion.

Table 5. Although $218(43.6 \%)$ participants agreed that a long lasting convulsion may indicate a worse prognosis, a majority $381(76.2 \%)$ did not know that, a focal convulsion may also indicate a similar worse outcome. The knowledge of the recurrent afebrile convulsion being epilepsy is almost equally agreed to- 235 , (47.0\%) and disagreed to- 204, (40.8\%). A majority, $418(83.6 \%)$ did not believe that treatment is available for convulsion at the hospital, while $400,(80.0 \%)$ believe that prophylaxis for convulsion is not available at the hospital. Some 371 participants $(74.2 \%)$ would rather treat convulsion at home, although a substantial proportion, $320(64.0 \%)$ agreed that home treatment is not timely applied. The majority of the participants, 418 , $(83.6 \%)$ however agreed that a child with convulsion is normal.

Table 6. The majority of the participants $421(84.2 \%)$, affirmed receiving health information regarding childhood convulsion with various sources being from health workers $(8.1 \%)$, neighbours $(11.6 \%)$, television $(17.2 \%)$, parents $(20.9 \%)$ and radio $(42.2 \%)$.

Table 7. The effect of education on the knowledge of convulsion (more prevalent among uneducated participants) was found to be significant for the erroneous belief that a child dies but regains consciousness after a convulsion ( $\mathrm{p}$ value $=0.000$ ), that angry gods may also cause a convulsion ( $\mathrm{p}$ value 0.009 ) and that malaria fever may be a cause of a convulsion ( $p$ value 0.029) However, education (among uneducated participants) was not found to affect the correct biomedical description of a convulsion, $\mathrm{p}$ value $=0.457$.

Table 1

Age group of participants

\begin{tabular}{lcl}
\hline Age group & No & $\%$ \\
\hline $18-27$ & 120 & 24 \\
$28-37$ & 200 & 40 \\
$38-47$ & 96 & 19.2 \\
$48-57$ & 64 & 12.8 \\
$\geq 58$ & 20 & 4 \\
\hline Total & 500 & 100 \\
\hline
\end{tabular}

Table 2

Some demographic characteristics of participants

\begin{tabular}{lll}
\hline Characteristics & No & \% \\
\hline Marital status & & \\
Single & 2 & 0.4 \\
Divorced & 7 & 1.4 \\
Widowed & 18 & 3.6 \\
Married & 473 & 94.6 \\
Total & 500 & 100 \\
Religion & & \\
Christianity & 94 & 18.8 \\
Islam & 406 & 81.2 \\
Traditional Religion & - & - \\
Total & 500 & 100 \\
Education & & \\
None & 167 & 33.4 \\
Primary & 168 & 33.6 \\
Secondary & 155 & 31.0 \\
Tertiary & 10 & 2.0
\end{tabular}




\section{Total \\ Occupation}

Farming

Trading

Housewives

Civil servants

Total

Ethnicity

Yoruba

Ibo

Hausa

Total

\section{0}

253

205

25

17

500

495

4

1

500
100

50.6

41.0

5.0

3.4

100

99.0

0.8

0.2

100

Table 3

Description of Convulsion

\begin{tabular}{|c|c|c|c|}
\hline \multirow{2}{*}{\multicolumn{4}{|c|}{$\begin{array}{l}\text { Description } \\
\text { Correct }\end{array}$}} \\
\hline & & & \\
\hline Clenching of the teeth & $500(100)$ & $0(\%)$ & $500(100)$ \\
\hline Stiffening of the arms and & $498(99.6 \%)$ & $2(1.4 \%)$ & $500(100)$ \\
\hline & $479(95.8 \%)$ & $21(4.2 \%)$ & $500(100)$ \\
\hline $\begin{array}{l}\text { Loss of consciousness } \\
\text { Twitching of the face and } \\
\text { or an extremity }\end{array}$ & $205(41 \%)$ & $295(59 \%)$ & $500(100)$ \\
\hline $\begin{array}{l}\text { Erroneous } \\
\text { Died but may regain life }\end{array}$ & $347(69.8 \%)$ & $153(30.2 \%)$ & $500(100)$ \\
\hline
\end{tabular}

Table 4

Causes of convulsion

\begin{tabular}{lllll}
\hline Causes & Yes $(\%)$ & No $(\%)$ & Don't know (\%) & Total (\%) \\
\hline $\begin{array}{l}\text { Correct } \\
\text { Malaria fever }\end{array}$ & $454(90.8)$ & $26(5.2)$ & $20(4.0)$ & \\
$\begin{array}{l}\text { Hereditary } \\
\text { Other }\end{array}$ & $338(67.6)$ & $62(12.4)$ & $100(20.0)$ & $500(100)$ \\
$\begin{array}{l}\text { illnesses } \\
\text { Erroneous }\end{array}$ & $97(19.4)$ & $292(58.4)$ & $111(22.2)$ & $500(100)$ \\
$\begin{array}{l}\text { Angry gods } \\
\text { Evil spirit }\end{array}$ & $259(51.8)$ & $82(16.4)$ & $159(31.8)$ & $500(100)$ \\
$\begin{array}{l}\text { Constipation } \\
\text { "Black blood" }\end{array}$ & $245(49.0)$ & $49(9.8)$ & $206(41.2)$ & $500(100)$ \\
& $184(36.8)$ & $300(60.0)$ & $16(3.2)$ & $500(100)$ \\
& $3(0.6)$ & $490(98.0)$ & $7(1.4)$ & $500(100)$
\end{tabular}

Table 5

Some knowledge on childhood convulsion

\begin{tabular}{|c|c|c|c|c|}
\hline Characteristics & Yes $(\%)$ & No $(\%)$ & Don't know (\%) & Total (\%) \\
\hline $\begin{array}{l}\text { Longer lasting } \\
\text { convulsion indicates } \\
\text { a worse convulsion }\end{array}$ & $218(43.6)$ & $175(35.0)$ & $107(21.4)$ & $500(100)$ \\
\hline $\begin{array}{lr}\text { Focal convulsion } \\
\text { indicates } & \text { worse } \\
\text { convulsion } & \end{array}$ & $57(11.4)$ & $381(76.2)$ & $62(12.4)$ & $500(100)$ \\
\hline $\begin{array}{l}\text { Recurrent afebrile } \\
\text { convulsions mean } \\
\text { epilepsy }\end{array}$ & $235(47.0)$ & $204(40.8)$ & $61(12.2)$ & $500(100)$ \\
\hline $\begin{array}{l}\text { Hospital treatment } \\
\text { is effective for } \\
\text { convulsion }\end{array}$ & $72(14.4)$ & $418(83.6)$ & $10(2.0)$ & $500(100)$ \\
\hline Prophylaxis for & $62(12.4)$ & $400(80.0)$ & $38(7.6)$ & $500(100)$ \\
\hline
\end{tabular}




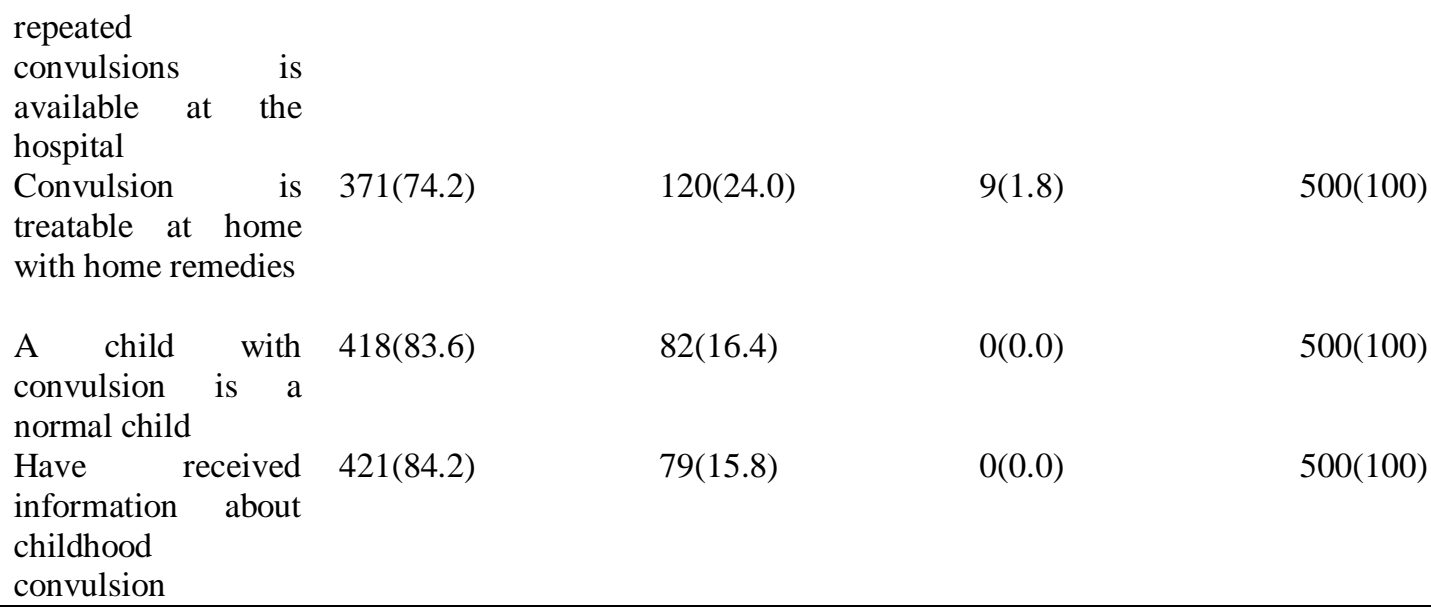

Table 6

Sources of information on childhood convulsion

\begin{tabular}{lll}
\hline Sources & No & $\%$ Responses \\
\hline Health worker & 43 & 8.1 \\
Neighbors & 62 & 11.6 \\
Television & 92 & 17.2 \\
Parent & 112 & 20.9 \\
Radio & 225 & 42.2 \\
Total & 535 & 100 \\
\hline
\end{tabular}

Table 7

Influence of education on some variables.

\begin{tabular}{lcc}
\hline Variable & $\boldsymbol{x}^{2}$ & $\boldsymbol{p}$-value \\
\hline Clenching of teeth & 2.60 & 0.457 \\
A child dies but regain consciousness & 24.34 & 0.000 \\
Malaria fever may cause a convulsion & 9.05 & 0.029 \\
Convulsion is caused by angry gods & 11.50 & 0.009 \\
\hline
\end{tabular}

\section{Discussion}

Clenching of the teeth was the commonest correct biomedical description of convulsion and the belief that a child dies but regains life, thereafter was found in $69.8 \%$ of the participants. In similar studies, as reported by Rutter and Metcalfe [13] in Britain, Deng [14] in Malaysia, Parmar et al [15] in India and Kayserili et al [16] in Turkey, 30\%, 70.9\% 90\% and 90\% of parents respectively, also believed in the misconception that a child dies but regains life after a convulsion. It may be inferred that the differences in the findings of this study and those of the other two studies may reflect the diverse socio-cultural beliefs about convulsion in these communities. Wherein, the erroneous description of convulsion in this study may be rooted in the belief that a person with convulsion is seized by a supernatural force or power as reflected by a Focused Group Discussant W2, who said "when a child is seized by convulsion, it stretches him out with the intent of killing the child but the child may not die if his destiny does not allow it". The emphasis is about referring convulsion to a "spirit person' who seizes a child and prompt him into a convulsion, a concept that contrasts the biomedical basis of convulsion.

A greater majority of the participants (90.8\%) believed that fever might be responsible for childhood convulsion, a finding that was higher than $14.4 \%$ of the subjects in Malaysia, [14] 22.1\% of Parmar et al [15] in India and 25\% of Ofovwe [12] who also believed that childhood convulsion may be due to fever. However, in most rural Nigerian homes, the concept of febrile convulsion is solely that due to malaria fever as this was emphasized in this study whereby a greater majority of (58.4\%), acknowledged that other febrile childhood illness cannot make a child convulsed.

Although, the correct knowledge that convulsion may be hereditary was found in $67.6 \%$ of the subjects, this acknowledgment may not be in consonance with the known biomedical model of heritable seizures. This may be inferred from the statement of FGD W4 to which other discussants agreed that "convulsion also runs in a family, it is a must that if the mother of a child has childhood convulsion, all her female children must also have it" 
The erroneous beliefs that constipation, an evil spirit and angry gods are capable of causing convulsion were found in $36.8 \%, 49.0 \%$ and $51.8 \%$ of the women respectively. Three women $(0.6 \%)$ also thought that 'black blood' may be responsible for childhood convulsion. Ofovwe et al [12] also found a greater majority $(75 \%)$ of the rural women attributing convulsion to witchcraft and or evil spirit. Furthermore, in the study of Rwiza [17] in rural Tanzania, $33.3 \%$ of women and a lower $7.0 \%$ and $2.6 \%$ of parents, in the hospital based study of Deng [14] in Malaysia and Kayserili et al [16] in Turkey, respectively, also believed that witchcrafts and an evil spirit are capable of causing childhood convulsion. Furthermore, Makundi [18] in Tanzania reported that $75 \%$ of mothers attributed convulsion to evil spirits. Various supernatural misconceptions of convulsion had been shown to perverse different communities and may also explain the differences in these studies. For example Makundi [18] had reported that among the rural folks, the evil spirit responsible for childhood convulsion is like a birdlike creature or a moth that enters into an 'unprotected child'. Also among the Bwatiye tribe of Northeastern Nigeria, Akogun and John [19] reported that that convulsion is regarded as an illness caused by evildoers and does not follow the biomedical concept of a disease entity whereby convulsion may complicate a febrile illness in its severe form. In the present study, W9, a focused group discussant said (and all other discussants agreed) that "definitely, convulsion is caused by the evil spirits or evil people who are set out to kill the child inflicted with convulsion. That is the reason many people seek for an herbalist to shout incantation to appease the evil spirit or the evil people so that the convulsion may be aborted". Although it may be easy to assume that erroneous supernatural beliefs about convulsion may be common among the un-educated rural folks as found in the present study, this finding may not be universal as Danesi [20] in Lagos, urban Nigeria, had earlier reported that formal education did not influence the correct knowledge about convulsion.

Although, $47.0 \%$ of women, rightly believed that repeated afebrile convulsion may be epilepsy. This acknowledgement, however may not reflect a true understanding among the subjects as all the focused group discussants agreed to an assertion by W7 that said "foaming in the mouth is related to epilepsy but clenching of the teeth and rolling up of the eyes is common to convulsion" This preposterous assumption may be a source of embarrassment to mothers who may be unwilling to seek help in the communal health centre for fear of stigmatization, as her child may be said to be having 'epilepsy', even when there is no correct justification for such diagnosis. In addition, 218 subjects (43.6\%) also correctly believed that the prognosis of convulsion is related to the duration; however a higher proportion, 381 subjects $(76.2 \%)$ did not know that a focal convulsion may portend a worse prognosis. It is a common knowledge, that a generalized seizure, unlike a focal seizure, presents more dramatically, capable of eliciting more panicking reactions from parents and caregivers and may explain why most subjects attributed it to a worse outcome .Also, a major proportion (83.6\%) of subjects agreed that appropriate hospital treatment is un-available for childhood convulsions and $80.0 \%$ did not know that prophylaxis may be available for convulsion in the hospital. These findings may not be difficult to explain as subjects would conclude that; if treatment is not possible in the hospital, then prophylaxis may also not be available. Furthermore, these findings are also supported by Rwiza [17] and Akogun and John [19] who also found that $50.8 \%$ and $100 \%$ of their subjects respectively did not believe that treatment for childhood convulsion is available at the hospital. There is a strong relationship between seeking for treatment and the perceived cause of an illness. For example among the Bwatiye people where Akogun and John [19] did their study, there is a strong belief in the spiritual causes of childhood convulsions and the confidence reposed in the local healer (the Boka) is legendary. It is believed that a convulsing child taken to another village by the Boka, out of reach of the local enemies is likely to survive than when treated in the same village.

A greater majority $(83.6 \%)$ believed that a child with convulsion was a normal child. This positive attitude was a significant finding that was emphasized during the Interventional health information in the community. However, a few subjects $(16.4 \%)$ thought that children with convulsion were not normal. This allusion may have been expatiated by two focused group discussants, W4 and W8. W4 said "yes, they are weaklings, that is why we don't engage such children in vigorous activities at home. W8 said "our fathers believed and we also believed it, that these children are 'Abikus' since their deaths are always heralded by these repeated convulsions. (Abikus are believed to be demon possessed children whose pre-mature deaths were predestined to punish the parents).

About $84.2 \%$ of the subjects claimed to have received health information about childhood convulsion and the fact that the majority of people (42.2\%) did so over the radio was not surprising as radio listenership was above $80 \%$ in Nigeria [21] and virtually most if not all homes have a radio transistor which is relatively cheap and is capable of being powered by readily affordable and available batteries. However, the apparent lack of sufficient and correct knowledge about childhood convulsion in the present study may not be unrelated to the details and the correctness or otherwise of the contents of such health information. Also television $(17.2 \%)$ and health workers $(8.1 \%)$ were other sources of health information on childhood convulsion in the present study. The relatively lower percentage of the subjects that have received health information via the health workers may be due to the fact that the majority of the subjects under the present study did not believe in the biomedical basis of childhood convulsion and thus would not seek information on convulsion from health workers. It may also 
reflect the fact that health workers often missed the opportunities of providing such vital information to the mothers for reasons bordering on insufficient time and/or wasted time on uncomplimentary comments and rebukes when mothers attested to the use of various home remedies for treating convulsions. In addition, 20.9\% and $11.6 \%$ of the subjects claimed to have received health information regarding childhood convulsion from parents and their neighbours respectively. In Tegbesun, like in any other African community, information regarding 'mysterious illnesses' are passed down and around from these aforementioned sources .Even when such information is erroneous, they are more strongly believed and may even override those heard from the electronic informants that are not seen or known.

\section{Conclusion}

The present study had revealed beyond reasonable doubts that there was a paucity of correct and adequate knowledge on childhood convulsion in Tegbesun, a peri-urban community in Ilorin, Nigeria. It showed that socio-cultural and religious beliefs about the causes of childhood convulsions were still firmly rooted among the women in the area of study. The effect of religion and ethnicity on the beliefs and behaviours of the participants towards childhood convulsion, although desirable was not statistically tested because reporting its findings may be offensive to this community. The findings of the study were however reported to the local Government Supervisory Councilor for Health (SCH). Firm action points regarding childhood convulsion were given to all the health workers, teachers and traditional health workers, residing in the community, in a meeting that was organized by the SCH. Health education was also given to women in Tegbesun via a role play, songs and proverbs regarding the causes, treatment and prevention of childhood convulsions. A post-Interventional study to determine the positive change in beliefs and behaviours of the women regarding childhood convulsion is desirable and it is therefore recommended.

\section{Acknowledgement}

The authors acknowledged Mallam Ajani Usman, The Alangua of Tegbesun, all the female participants and the medical students for their cooperation during the study.

\section{References}

[1] Haslam RHA, The nervous system in RE Behrman, RM Kliegman, HB Jenson, (Eds.), Nelson Textbook of Paediatrics, (Philadelphia : WB Saunders; 2000) 1813-1826.

[2] Angyo IA, Lawson JO, Okpeh ES, Febrile convulsions in Jos, Nig J Paediatr, 24, 1997, 24:7-13.

[3] Fagbule D, Chike-obi UD, Akintunde EA, Febrile convulsions in Ilorin, Nig J Paediatr, 18, 1991, $23-27$.

[4] Osuntokun BO, Convulsive disorders in Nigerians, East Afr Med J, 46, 1969, 385-394.

[5] Izuora GI, Azubuike JC, Prevalence of seizure disorders in Nigerian children around Enugu (A preliminary report), Cent Afr J Med, $23,1977,80-83$

[6] Obembe A, Ahmed MH, Epilepsy in Kaduna, a study of 164 youths, Nig Med Pract, 16, 1988, 45-48.

[7] Danesi MA, Classification of the epilepsies; an investigation of 945 patients in a developing country, Epilepsia, 26, 1985, $131-136$.

[8] Dada TO, The epilepsies; their incidence and causation in Nigeria in Proc. $7^{\text {th }}$ International symposium on Epilepsy, Berlin, 1975, 24.

[9] Iloeje SO, The impact of socio-cultural factors on febrile convulsions in Nigeria, West Afr J Med, 8, 1989, 54-58.

[10] Okoji GO, Peterside IE, Oruamabo RS, Childhood convulsions: a hospital survey on traditional remedies, Afr J Med Sci, 22, 1993, 25-28.

[11] Anochie I, Graham-Douglass IB. Non-accidental injuries associated with convulsions in Port-Harcourt, Nigeria. Anil Aggrawal's Internet Journal of Forensic Medicine and Toxicology. [Internet]. 2000 [cited 2006 Nov 29]; 1 (. 2). : Available from http://www.anilaggrawal.com/ij/vol_001_no_002/paper009.html .

[12] Ofovwe GE, Ibadin OM, Ofovwe EC, Okolo AA, Home management of febrile convulsion in an African population: a comparison of urban and rural mothers' knowledge, attitude and practice, J Neurol Sci, 200, 2002, 49-52.

[13] Rutter N, Metcalfe DH, Febrile convulsions, what do parent do, Br Med J, 2, 1978, 1345-1346.

[14] Deng CT, Zulkifli HI, Azizi BH, Parental reactions to febrile seizures in Malaysian children, Med J Malaysia, 4, 1996, 462-368.

[15] Parmar RC, Sahu DR, Bavdekar SB, Knowledge, attitude and practices of parents of children with febrile convulsion, J Postgrad Med, 47, 2001, 19-23

[16] Kayserili E, Unalp A, Apa H, Asilsoy S, Hizarcioglu M, Gulez P, Agu H, Parental knowledge and practices regarding febrile convulsions in Turkish children, Turk J Med Sci, 38, 2008, 343-350.

[17] Rwiza HT, Matura WBP, Kilonzo GP et al, Knowledge, attitude and practices towards epilepsy among rural Tanzania residents, Epilepsia, 6, 2008,1017-1023.

[18] Makundi EA, Malebo AM, Mhame p et al, Role of traditional healers in the management of severe malaria among children below five years of age; the case of Kihosa and Handeni districts, Tanzania, Malar J, 5, 2006,58-64.

[19] Akogun OB, John KK, Illness related practices for the management of childhood malaria among the Bwatiye people of northeastern Nigeria, Malar J, 4, 2005, 13-16.

[20] Danesi AM, African aspects, in M Dam M, I Gran (Eds.), Comprehensive epileptology, (New York: Raven press 1990) $795-805$.

[21] National Population Commission. Socio-demographic Data 1993: p. 4. 